Published in final edited form as:

Popul Res Policy Rev. 2017 June ; 36(3): 309-330. doi:10.1007/s11113-016-9424-y.

\title{
Life Course Changes in Smoking by Gender and Education: A Cohort Comparison Across France and the United States
}

\author{
Fred C. Pampel, \\ Institute of Behavioral Science, University of Colorado, Boulder, 80309-0483 USA \\ Damien Bricard, \\ Institut de Recherche et Documentation en Economie de la Santé (IRDES), Paris, France \\ Myriam Khlat, and \\ Institut National d'Etudes Demographiques, 133, boulevard Davout - 75020 Paris, France \\ Stéphane Legleye \\ INSERM U1178, Université Paris-Sud, UVSQ, Université Paris-Saclay, Villejuif, France
}

\begin{abstract}
Widening of educational disparities and a narrowing female advantage in mortality stem in good part from disparities in smoking. The changes in smoking and mortality disparities across cohorts and countries have been explained by an epidemic model of cigarette use but are also related to life course changes. To better describe and understand changing disparities over the life course, we compare age patterns of smoking in three cohorts and two nations (France and the United States) using smoking history measures from the 2010 French Health Barometer $(N=20,940)$ and the 2010 U.S. National Health Interview Survey Sample Adult File $(N=20,444)$. The results demonstrate statistically significant widening of gender and educational differences from adolescence to early and middle adulthood, thus accentuating the disparities already emerging during adolescence. In addition, the widening disparities over the life course have been changing across cohorts: Age differences in educational disparities have grown in recent cohorts (especially in France), while age differences in gender disparities have narrowed. The findings highlight the multiple sources of inequality in smoking and health in high-income nations.
\end{abstract}

\section{Keywords}

Smoking; Cohort; Life course; Education; Gender

\section{Introduction}

Public health concerns have followed from two disparate trends in mortality, one involving a decline in gender disparities and another a rise in education disparities. For gender, the slowed rate of mortality decline among women relative to men has reduced the male disadvantage but also limited the gains to women. The recent trends reverse nearly a century of rising female mortality advantage (Glei and Horiuchi 2007). For education and other components of socioeconomic status (SES), studies have noted for decades that disparities have been steadily rising (e.g., Montez et al. 2011; Pappas et al. 1993). The persistence of 
these health inequalities, which are enduring enough to treat SES as a fundamental cause of health (Masters, Link, and Phelan 2015; Montez and Barnes 2016), has been called one of the great disappointments of public health (Mackenbach 2012).

Although many factors contribute to changing trends and patterns in mortality, the importance of tobacco use to premature death in general and to gender and educational disparities in particular is indisputable. The yearly 480,000 deaths in the United States estimated to come from tobacco make this habit the single most preventable cause of death in the country (USDHHS 2014). In Europe, an estimated 16\% of all deaths of adults age 30 and over are due to smoking (WHO 2016). Further, the gendered trends in smoking have contributed importantly to narrowing mortality rates between men and women (Luy and Wegner-Siegmundt 2015; Thun et al. 2012, 2013), and educational differences in smoking explain up to $50 \%$ of the educational differences in mortality (Jha et al. 2006; Wong et al. 2002). Given the clear harm of tobacco, the persistence of the habit among one-fifth to onethird of adults in the United States and Europe, and the lag between smoking and death, the gender and education-based trends in smoking foretell continued mortality disparities in the future. These facts emphasize the value of studying smoking in its own right: understanding patterns and trends in smoking are crucial to understanding population patterns and trends in mortality more generally.

An epidemic model of cigarette use has been useful in describing patterns of change overall and among gender and education groups (Lopez, Collishaw, and Piha 1994). The model is based on the historical timing of the initial adoption of cigarettes, the early spread among men, the later spread among women, the subsequent partial reversal among men, and the partial reversal among women. Underlying the model is the argument that men began using cigarettes first, and given the constraints on women's behavior, they followed in adoption of smoking only after a lag of several decades. The decline in smoking also began first among men and occurred more slowly among women. The different timing of the epidemic among men and women has led to gender convergence in smoking prevalence, smoking-related diseases such as lung cancer, and mortality overall. Studies demonstrating support for the predicted pattern of change have examined long-term differences in smoking across cohorts and countries (Pampel 2003).

The epidemic model has been extended with diffusion theory to include differences in cigarette use by SES (Ferrence 1989; Giskes et al. 2005; Mackenbach et al. 2004; Pampel 2002). The logic here is that groups with more education and higher income adopt innovations earlier than others and that cigarette use represented a form of innovation during the early part of the 20th century. After a lag, the new behavior diffused to others and less innovative groups followed in adoption. Similarly, groups with more education and higher status were the first to reject smoking, with other groups changing more slowly. The rapid decline in smoking among advantaged groups, which are farther along in the epidemic relative to less advantaged groups, thus contributed to the widening disparities of recent decades. This pattern has shown in diverse countries and cohorts (Giskes et al. 2005; Mackenbach et al. 2004; Pampel et al. 2015). 
In addition to the broad trends posited by the epidemic model, another source of gender and educational disparities in smoking relates to within-cohort changes over the early life course. Consistent with a life course approach, the means and motives for smoking differ substantially between adolescence and early to middle adulthood (Chen and Jacobson 2011; Costello et al. 2008; Harman et al. 2006). Adolescents appear to make decisions about smoking without full understanding and analysis of the risk (Slovic 2001). Thus, initiation rises steadily during the teen years, while initiation is rare and cessation becomes increasingly common at older ages (USDHHS 2014). Life course stage influences not only the levels of smoking but may also influence gender and education differences in smoking. As late initiation and cessation rates differ by gender and education, the disparities that emerge in adolescence may be strengthened in early adulthood. Evidence for this approach shows in longitudinal studies (Bachman et al. 2002; Pampel et al. 2014).

The objectives of this paper are to 1) examine how gender and educational differences in smoking vary across the life course and 2) compare life course inequalities across cohorts and nations. We thus combine the attention of the epidemic model to long-term trends in smoking with the study of life-course changes in smoking within cohorts. Both perspectives are valuable but are rarely studied in combination.

Based on this approach, we examine the evolution of life course patterns in gender and educational disparities in smoking across cohorts born between 1941 and 1985 in France and the United States. Because cohorts serve as a vehicle of change in smoking, they are crucial for tracing the social patterning of the epidemic. Additional diversity in life course patterns comes from comparing two countries, one of which began the epidemic later (France) than the other (United States). The next sections describe theoretical arguments and list hypotheses that are drawn from both the life course and epidemic approaches. The following sections then present a method for testing the hypotheses that uses data on age patterns of smoking prevalence by gender and education for multiple cohorts and countries.

\section{Life Course Changes and Smoking}

The life course perspective recognizes that early life conditions and experiences have enduring influences on adult conditions and experiences, thus creating some coherency and meaning in the life course (Elder 1994). In specifying the nature of these linkages, theories of cumulative advantage argue that favorable conditions during childhood become a resource leading to future gains. The steady, incremental accumulation of advantages does more than maintain inequality over the life course - it also widens the difference in relative positions between groups. The perspective has helped to explain the maintenance of socioeconomic inequality both within and across generations (DiPrete and Eirich 2006; Willson, Shuey, and Elder 2007) but extends to health inequality as well (Lacey et al. 2010; Staff et al. 2010). It emphasizes that life course experiences in adolescence affect later health (Zajacova, Walseman, and Dowd 2015) by launching social and health trajectories into motion (Umberson, Crosnoe, and Reczek 2010).

For cigarette smoking, however, life course patterns are subject to special forms of modification during the transition from adolescence to young adulthood. Although some 
disparities in smoking emerge early (Droomers et al. 2005; Soteriades and DiFranza 2003), SES background and gender differences in smoking are small during adolescence and in some studies absent altogether (Hanson and Chen 2007; Jacobson et al. 2001; Johnston 2001; Tuinstra et al. 1998). Yet late initiation (Moon-Howard 2003) and low cessation of tobacco use among less educated groups and males may widen disparities during the adult years (Chassin et al. 2000; Hu et al. 2008). The bulk of disparities come from early initiation versus never smoking (Maralani 2013), but differences in late initiation and cessation may have influence as well. Adult experiences thus have the potential to redirect adolescent trajectories in ways that widen gender and education disparities.

First, gender differences in smoking may be larger for adults than adolescents. During the adolescent years when both genders are prone to experiment, boys and girls may smoke similarly. Special body concerns, desire for thinness, and dieting may even encourage greater smoking among adolescent girls (Potter et al. 2004). In a study of 15 -year olds using 1998 data from seven European countries, Griesbach, Amos, and Currie (2003) report higher smoking among girls than boys in each country. Another study of cigarette use in the last 30 days by youth ages 15-16 found gender differences for only 11 of 36 European countries (with sample size of at least 2500 in each country), and five of the countries (including France) showed higher prevalence among girls (Hibeli et al. 2012:67). For the United States, data from 2013 on 30-day smoking among 12th grade students show minimal gender differences (Johnston et al. 2014:47). In young and middle adulthood, however, women face special risks from smoking that are related to childbearing (Graham, Hawkins, and Law 2010; Ingall and Cropley 2010; Oaks 2001). During this part of the life course, women may have stronger motivations than men to avoid tobacco, their levels of smoking may decline more, and gender divergence may follow.

Second, education differences may be larger for adults than adolescents (Lacey et al. 2010). Women and men with high education tend to smoke socially during schooling years (Nichter 2015), but being less addicted to nicotine and having more resources for cessation, they can more easily quit during adulthood or on entrance into the workforce and childbearing (Bosdriesz et al. 2015; Harmon et al. 2006; Reid et al. 2010). In contrast, women and men with low education adopt smoking more often as a coping device to deal with stress, become more addicted, and have fewer resources to help quit (Businelle et al. 2010; Peretti-Watel and Constance 2009; Peretti-Watel et al. 2009). Although smoking levels may be similar during adolescence, the motives and circumstances differ enough across education groups to produce divergence in young and middle adulthood (Pampel, Mollborn, and Lawrence 2014).

\section{The Epidemic Model and Life Course Changes in Smoking}

The epidemic model suggests that patterns of smoking differ substantially across cohorts and countries. First, older cohorts raised earlier in the 20th century, when cigarette use was growing and health concerns were minimized, had high levels of smoking, large gender differences, and modest educational differences. Younger cohorts raised at later stages, when cigarette use was declining and health concerns were prominently publicized, had lower levels of smoking, larger educational differences, and smaller gender differences. Second, 
European countries entered into the cigarette epidemic later than the United States (Pampel 2002), and the later start helps explain the currently higher smoking in Europe. For example, the number of cigarettes sold per adult per day peaked in the United States in 1961 at 10.7, while it peaked considerably later in France in 1985 at 6.0 (Forey et al. 2016). Consistent with the stage of diffusion, European countries have smaller educational disparities and larger gender disparities than the United States (Pampel et al. 2015).

Life course changes in gender and educational disparities in smoking may vary with the evolution of these disparities across cohorts and countries. The arguments for gender and education differ in some ways but both posit that the cohort and country contexts of smoking shape the nature of life course changes. First, as the epidemic serves to widen education disparities in younger cohorts and in countries farther along in the epidemic, life course changes consistent with the trends should also widen disparities. It follows that life course widening of educational disparities will be greater in younger cohorts than older cohorts and in the United States than France. Second, as the epidemic narrows gender differences, life course widening of gender disparities should be smaller in younger than older cohorts and in the United States than in France. As gender differences narrow overall, they should also narrow over the life course.

A few studies have compared smoking disparities over the life course. Legleye et al. (2011) and Bricard et al. (2015) examined the age-based timing of initiation and cessation across gender and education groups in France. They found evidence of widening educational inequalities and narrowing gender inequality across cohorts. Adding a comparative component, Pampel et al. (2015) examined the timing of smoking initiation across cohorts in France, Germany, and the United States. They found that the emergence and growth of educational disparities and changes in gender disparities occurred earlier in the United States than in France and Germany. However, in examining initiation, they did not measure cessation or fully describe disparities in prevalence over the life course.

\section{Hypotheses}

The focus on life course changes for gender and educational groups across cohorts and countries defines several hypotheses:

- $\quad$ H1: Gender differences in smoking will widen from adolescence to early and middle adulthood, as women respond to special risks related to childbearing.

- $\quad \mathrm{H} 2$ : Widening of gender disparities over the life course will be weaker in younger cohorts and the United States, as overall gender differences in smoking decline at later stages of the cigarette epidemic.

- $\quad$ H3: Educational differences in smoking will widen from adolescence to early and middle adulthood, as more highly educated social smokers are better able to use resources to avoid smoking.

- H4: Widening of education disparities over the life course will be stronger in younger cohorts and the United States, as overall education differences in smoking increase at later stages of the cigarette epidemic. 


\section{Methods}

\section{Data}

Data come from two comparable surveys: 1) the French Health Barometer 2010, a representative nationwide telephone survey of the non-institutionalized population aged 15-85 (Beck et al. 2011a, 2011b); and 2) the 2010 U.S. National Health Interview Survey Sample Adult File, a representative nationwide face-to-face survey of individuals ages 18 and older within households and non-institutional group quarters (National Center for Health Statistics 2013). For the population studied here, men and women at ages 25-69 with complete education and smoking data, the sample sizes equal 20,940 in France and 20,444 in the United States.

In France, the survey used a two-stage simple random sample: household (with random digital dialing and including mobile phones) and then one person within the household (Kish method based on the age and gender composition of the household). The response rate was $60.5 \%$. Weights adjust for survey design, non-response and the proportion of mobile phones and use a calibration process based on age, sex, diploma, employment status and region to match the distribution of the last national Labor Force Survey. In the United States, the survey used a stratified multistage procedure that oversamples minority groups. The response rate was $60.8 \%$. Weights adjusted for design, non-response, and post-stratification adjustment (to match the age-sex-race/ethnicity distribution in the census).

The comparison of France and the United States, given the different stages of the cigarette epidemic in the two countries, is well suited for testing the hypotheses. Pampel (2003) measured the peak year of the smoking epidemic, reporting an earlier peak in the United States (1955) than France (1978) - an indication of the earlier start of the U.S. epidemic. Pampel et al. (2015) further demonstrated the later stage of the United States by showing an earlier emergence of educational disparities than in Germany or France. Another reason for our choice is that France and the United States each have surveys with comparable designs and identical measures of age at initiation and age at cessation. Although not generalizable to other high-income nations, the comparison of two countries improves on the more common study of a single nation.

\section{Measures}

Each data set measures the age at smoking uptake for those who had ever smoked regularly. In the French data, uptake referred to regular/daily smoking ("A quel âge avez-vous commencé à fumer régulièrement, i.e. tous les jours?”) with a follow-up probe on daily smoking for uncertain respondents. This question was asked to current regular or former regular smokers (who had been smoking at least six months). In the U.S. data, uptake referred to regular smoking ("How old were you when you FIRST started to smoke fairly regularly?"). This question was asked to current or former smokers (who had smoked 100 cigarettes in their lifetime). Similar questions asked former smokers at what age they quit smoking. Questions on age of starting and stopping to smoke can be used to construct an accurate age-specific tobacco-use history for each respondent (Bilal et al. 2014). To describe life course patterns, we create person-age data for a dichotomous measure of smoking.

Popul Res Policy Rev. Author manuscript; available in PMC 2018 June 01. 
Education was measured in four categories. To be comparable across countries, these categories are coded from national diploma typologies using ISCED standards (UNESCO 2015): 1) ISCED 0, 1 and 2 levels: below upper secondary education (Low); 2) ISCED 3 and 4: upper secondary education and post-secondary non-tertiary education (Medium); 3) ISCED 5: short-cycle tertiary education (High-short); 4) ISCED 6 and over: at least a Bachelor's degree or equivalent level (High-long). In the USA, the category "some college, no degree" is not a formal credential but differs from a high school degree only and, as recommended by Kerckhoff, Ezell, and Brown (2002), is classified in the first level of tertiary education (ISCED 5, High-short).

The analysis sample was restricted to respondents who were at least 25 years old at the time of the survey, so as to take the final educational level reached into account, and to subjects under 70 so as to minimize recall problems and selection biases resulting from differential mortality (Christopoulou et al. 2011). Age in 2010 was used to define three cohorts for comparison: ages 55-69 (born 1941-1955), ages 40-54 (born 1956-1970), and ages 25-39 (born 1971-1985). To make the comparisons of smoking meaningful across cohorts, the ages of initiation for the older cohorts are restricted to a maximum of age 39, the upper bound of the youngest cohort. Initiation after those ages is considered censored.

Given the focus on initiation during adolescence, before schooling is completed, education serves here as a general indicator of social and economic characteristics associated with future socioeconomic advantage. The relationship between education and smoking encompasses the influences of factors such as "differences in time preferences, aspirations, friends and social networks, risk preferences, and cognitive and noncognitive skills" (Maralani 2013:130). Given the timing inconsistencies, we avoid attributing causal importance to years of schooling or degree by themselves but use the measure as a broad indicator related to health advantages that emerge early in the life course. Whatever the underlying sources of the relationship between education and smoking, the existence of disparities lends importance to the measurement and study of the relationship.

\section{Empirical Strategy}

Smoking patterns by gender, education, and cohort for France and the United States are described by prevalence of smoking from age 14 to 39 . Three figures present the gender difference in smoking prevalence over the life course. Figure 1 presents the life course evolution of smoking prevalence by gender for each cohort and country considering all levels of education together. Figures 2 and 3 display these changes for low education and high education levels separately. We present these two extreme groups for parsimony and because the intermediary groups show graduated results.

For the analysis, the data are pooled by year of age for each individual from ages 14 to 39 or current age. For each case defined by person and age, the outcome equals a binary measure of currently smokes or not. Discrete-time regression models with adjustment of standard errors for clustering within individuals are used to compare the life course evolution of smoking prevalence by gender and education for the age-person data (Allison 1982). The models control for gender and follow-up age in categories $(14-19 ; 20-24 ; 25-29 ; 30-39)$ and also include cohort as year of birth to control for smoking differentials within the 15-year 
cohorts. We first test for gender differences in smoking patterns during the life course by including interaction terms of gender and age in categories (Model 1). As males and ages 14-19 serve as reference categories, the interaction terms estimate the extent of changes in gender differences from adolescence to older ages. The combined test of significance of interaction terms and a linear trend test over the age categories are used to summarize the results.

Using the same strategy, we also test for education differences in smoking patterns during the life course by including interaction terms of education and age in categories (Model 2). The interaction terms estimate the differences between the lowest educational category (reference) and each of the other educational categories for each of the age categories. The combined test of significance of interaction terms and a linear trend test over the age categories by educational level help to summarize the results.

Finally, after these two series of two-way interaction tests between age and gender/ education, we also consider the possible combined influence of age, gender and education by testing a model with a three-way interaction.

For all these analyses, we use a linear probability model to interpret gender and educational differences directly as an absolute measure of the difference (or gap), which focuses directly on a probability scale and makes the interpretation of the interactions easier. Logit and probit models with interaction terms to make comparisons across groups have well-known limitations (Allison 1999) and involve considerable complexity in interpretation (Ai and Norton 2003). Linear probability models avoid these problems and with our large sample size give similar results to logistic regression in terms of statistical inference. We also correct models for individual clustering over ages and heteroscedasticity using robust standard errors. We perform the analysis by cohort and country separately. Note that checks with logit models show that the linear probability estimates are robust. Given the special problems in interpreting interactions in logit models, the coefficients cannot be compared directly to the regression-based interaction coefficients presented in the tables. However, logit models can be compared more meaningfully to additive linear probability models with marginal probability effects calculated at the means of the model predictors. We therefore examined the effects of gender and education within each of 12 groups (four age groups by three cohorts). The two sets of models gave nearly identical results.

\section{Results}

The distribution by education differs across the two countries (Table 1). The mode equals the second educational category (premier et second cycle hors baccalauréat) in France and, with one exception, the highest educational category (college degree) in the United States. Across cohorts, France shows a major decline in the proportion in the lowest category and more modest increases in the others. The United States shows more stability, with the largest decrease occurring among women attaining a high school degree and the largest increase occurring among women attaining a college degree. Women have lower educational attainment in the older cohorts in both nations, but not in the youngest cohort.

Popul Res Policy Rev. Author manuscript; available in PMC 2018 June 01. 


\section{Gender Differences over the Life Course}

The graphs first demonstrate convergence across cohorts in prevalence of male and female smoking (Figure 1). In France, the gender gap at age 25 falls from 32.7 percentage points (54.4 - 21.7) in the oldest cohort to $9.6(50.5-40.9)$ in the youngest cohort. Being farther along in the epidemic, the gender gap is smaller in the United States, especially for the oldest cohorts, but the gap narrows from 15.2 to 7.8 .

In support of hypothesis 1, the gender gap appears narrower in adolescence - rates reach near parity before age 20 in the youngest cohorts - than in young and middle adulthood. The top panels of Tables 2 and 3 (Model 1) present tests for gender differences in life course patterns with the age categories (14-19 reference, 20-24, 25-29, and 30-39). For France, the female-by-age coefficients in Table 2 show that the differences in smoking between men and women are significantly larger (i.e., more negative) for all three age groups and all three cohorts. The interaction F-tests show significant differences for all three age groups combined relative to ages 14-19, while the trend test confirms that the gender gap increases slowly with age (from 14-19 to 30-39). Although gender differences widen across ages in all cohorts, the differences are smallest for the youngest cohort. Compare for example the difference between ages 14-19 and 30-39 for the oldest cohort $(b=-.12)$ and the next two cohorts $(b=-.03$ and -.06$)$. These cohort differences support hypothesis 2 . For the United States, significant female-by-age interactions support hypothesis 1 (Table 3), but the differences are smaller and more similar across cohorts than in France. The smaller widening of age-based gender differences in the United States further supports hypothesis 2.

Comparing gender differences over the life course by level of education further differentiates the patterns (Figures 2 and 3). For the low education groups in Figure 2, gender convergence occurs to a limited degree. The gap at age 25 rises from cohort 1 to 2 in the United States and then declines to 8.9 percentage points from cohorts 2 to 3 . France evidences greater convergence from cohort 1 to cohort 2 but little change afterward. The gender gap for cohort 3 remains at 15.6 percentage point. The prevalence level changes little for men and rises considerably for women. In contrast, the United States shows some decline in both groups.

For those with high education, a pattern of convergence during adolescence and divergence afterwards emerges. By cohort 2 in France and the United States, and even more strongly in cohort 3 of France, female smoking during adolescence exceeds or equals male smoking. At older ages, however, male smoking exceeds female smoking. The adult gender gaps are smaller in younger cohorts than the oldest cohort but are apparent in all comparisons of high education groups. To varying degrees, then, the gender gap appears larger later in the life course and supports hypothesis 1.

\section{Educational Differences over the Life Course}

We also examine changes in educational differences in smoking prevalence over the life course using a similar strategy (Model 2). In the bottom panels of Tables 2 and 3, interaction terms for education-by-age allow the differences between the lowest education group and each of the other groups to vary with age category. At ages 14-19, the results confirm the presence of educational inequalities in smoking: the coefficients for the reference effect of

Popul Res Policy Rev. Author manuscript; available in PMC 2018 June 01. 
education (at 14-19) show a gradient with lower prevalence for high education group for all cohorts in France and the United States. Of more importance for tests of the hypotheses, the education-by-age interaction coefficients show changes in educational disparities at older ages. In general, the results support hypothesis 3 in showing evidence of greater disparities at older ages, and they support hypothesis 4 in showing that the widening disparities are stronger for younger cohorts than older cohorts and for the United States than France. For the oldest cohort in France, small educational disparities in adolescence (-.04 for high education) get smaller at ages 30-39 $(-.04+.07)$. Yet, for the youngest cohort in France, the large educational disparities in adolescence (-.21 for high education) get even larger at ages $30-39(-.21-.10)$. The change across cohorts is summarized by the Trend for high education, which reverses from positive (.02) in the oldest cohort to negative in the youngest cohort (-.03).

In the United States at ages 14-19 (Table 3), the negative education-by-age interaction terms and the negative linear trend for high education of -.01,-.02, and -.02 indicate widening of disparities at older ages, again supporting hypothesis 3. Further, in support of hypothesis 4 , the widening of education disparities increases across cohorts, though not by a large amount. At ages 30-39, the effects for high education are -.18 (-.15 - .03) for the oldest cohort and -. $19(-.13-.06)$ for the youngest cohort.

The results provide some additional support for hypothesis 4 , that the widening across age is greater in the United States than France. The widening is stronger in the United States for the two oldest cohorts but has become more similar across countries for the youngest cohort. For example, the effect of high education at ages 30-39 is .07, -.01, and -.10 in France, and -. 03, -.05, and -.06 in the United States.

Also note that in France, the strengthening of education differences is apparent for the highest and next-to-highest education group, whereas in the United States, the pattern is apparent only for the highest college-educated group. For example, for the youngest cohort at ages 30-39 in France, the probability of smoking is -.24 (-.16- .08) lower for the next to highest educational group and -.31 (-.21 - .10) for the highest education. In the United States, the probability of smoking is -.19 (-.13 - .06) lower for the highest educational group but only $-.03(-.02-.01)$ for the next highest educational group.

Additional tests address the question of whether gender differences in life course patterns vary by level of education. The three-way interaction terms between age, education, and gender seldom reach statistical significance and, when they do, reflect more in the way of randomness than a systematic pattern. Thus, age patterns of smoking vary by education and vary by gender but do not vary by the combined categories of education and gender. This null outcome highlights the fundamental role played by the social position (diploma) for smoking inequality, as it indicates that men and women show similar educational disparities over the life course. Conversely, it also shows that gender disparities over the life course are similar within educational groups. 


\section{Discussion}

Smoking represents a crucial outcome for the study of the social distribution of health because of its singular negative influence on health and longevity and its strong relationship to social and economic disadvantage. In addition, gender and education differences in smoking across stages of the cigarette epidemic and stages of the life course have importance for public health policy. Our approach to understanding gender and educational disparities in health links two theoretical perspectives, one focused on life course changes and one on the cigarette epidemic. The four hypotheses following from the theories relate not only to gender (H1) and education (H3) but also to cohort and nation (H2 and H4). We test the hypotheses by comparing age differences in smoking by gender and education across three broad cohorts and two countries.

In support of the hypotheses, we show a general tendency for gender and educational differences to widen from adolescence to early and middle adulthood (hypotheses $\mathrm{H} 1$ and H3). This age pattern accentuates disparities only beginning to emerge during adolescence. In addition, our results on education show that the effect of age on educational inequalities is changing across cohorts: age does more to widen inequalities in more recent cohorts (hypothesis H4). In contrast, gender differences consistently increase with age, but in a more moderate way in the most recent cohort (hypothesis H2). Also consistent with hypotheses $\mathrm{H} 2$ and H4, the changes across cohorts are more apparent in France than the United States. However, we find little evidence that these age patterns vary across combined gender and education categories, which suggests that the effect is more of an additive nature than of a multiplicative nature. Some more specific implications follow from these general findings.

\section{Gender Patterns}

The results show a tendency of male and female smoking to converge in recent cohorts, particularly during adolescence and for the highly educated. But this tendency to converge over cohorts is accompanied by a tendency to diverge over the life course, as female smoking declines starting from young adulthood. This divergence of male and female smoking over the life course occurs across cohorts and countries (H1), but appears stronger in earlier than later cohorts and in France than the United States (H2).

In relation with this observation, one question which has been raised in the literature is whether there will be a cigarette consumption cross-over between men and women, and whether in the long run the female advantage in terms of survival will be threatened due to rising female lung cancer death rates concomitant to falling male lung cancer death rates. We indeed find that there is a cross-over in the last cohorts in France and in the middle cohorts in the United States among the highly educated, but this cross-over is limited to adolescence and very early adulthood, and that, starting from a threshold of around 20-24 years, i.e., from the start of childbearing ages, the consumption of females falls below that of males. Therefore, the eventual crossover is limited to an early period in the life course and to the highly educated, among which the consumption had already fallen quite low. This protective life course pattern of female smoking prevalence does not support the idea that female lung cancer rates will surpass those of males. In addition, we may expect that the gender differences over the life course would increase with cohorts when women face their 
first pregnancy, as the medicalization of pregnancy and the efforts in the prevention of tobacco smoking have been much more pronounced over time. But the contribution of being aged 20-24 or 25-29 compared to being aged 15-19 is not increasing the gender difference over cohorts. This reflects in fact a similar tendency of men and women to stop smoking at these ages in the most recent cohorts.

\section{Education Patterns}

Results also show historical and life course patterns of educational differences. For all cohorts and countries, educational differences in smoking are found in adolescence and they tend to increase with age (H3). In addition, the cohorts differ in terms of life course changes. In the oldest cohort and for some educational groups in the intermediate cohort, we find that educational inequalities tend to taper over age. In contrast, we find for the most recent cohort a widening of inequalities with increasing age both in France and in the US (H4).

A life course pattern of increasing difference suggests that, after an early phase of experimentation, there are different cessation dynamics in different educational groups. Those attaining additional education tend to experiment then quit at the threshold of adulthood, whenever confronted to family and work constraints, and this applies particularly to women during their childbearing ages. This type of life course pattern (experimenting then quitting) is somewhat similar to the temporal trend in the diffusion model: initial spread followed by rejection.

This life course pattern of early initiation and discontinuation at entry into adulthood is very specific to the social roles and health awareness of more educated groups, and much less visible in groups with less education that pursue the habit well into adulthood, particularly in the most recent cohorts, in which smoking is on the rise compared to older cohorts. We must qualify these findings and conclusions by noting that we are unable to identify the causal sources of the relationship between education and smoking. The relationship involves more than formal schooling and learning, as smoking typically emerges before the completion of education. Nonetheless, even without a causal analysis, describing variation in the education-smoking relationship across age, cohort, and country offers insights into the nature of the disparities and the targets for policy change.

\section{Policy Implications}

The study of life course changes in smoking suggests that understanding adult life course transitions may help in planning public policy. It raises the issue of population approaches versus more targeted policies for tobacco reduction. A population approach to public health (Rose 1985, 1992) advocates mass environmental interventions such as raising tobacco prices and restricting use of tobacco in public places. These programs have contributed importantly to lowering overall smoking prevalence in the United States and European countries. Several studies and reviews further suggest that clean air laws and price increases benefit disadvantaged groups (Dinno and Glantz 2009; Schaap et al. 2008; Thomas et al. 2008). However, there is some concern over the potential for population-level policies to worsen inequalities in smoking (Frohlich and Potvin 2008). Our results suggest that policies based on aggregate prevalence over all ages may miss key points of transitions during the 
early adult life course and the transition to adulthood, and therefore do less to lower smoking for disadvantaged groups and worsen inequalities.

\section{Limitations}

The results are limited by the focus on two nations, however. Differences in results across France and the United States can result from sources other than stage of the cigarette epidemic, such as the educational system, marketing and sales regulations, and cultural norms and attitudes. As part of a general theory, the epidemic and diffusion arguments apply to other countries and offer explanations to go beyond unique characteristics of particular countries. Replicating the results for other nations with different histories of smoking adoption and anti-smoking policies can give insight into the generality of findings about changing smoking disparities over the life course and our tests of the theory. Extension of the cohorts studied to those born more recently and subject to the growth of anti-smoking policies would likewise be helpful, although such efforts must await future data. The results are also limited by the use of retrospective data. Studies suggest that recollections of starting and stopping age are generally accurate (Bilai et al. 2014), and that differential mortality has only small effects on cohort comparisons of educational disparities (Pampel 2005). It is still possible that older cohorts have weaker disparities because less educated smokers die sooner and less accurately recall their earlier smoking. Yet, support for the diffusion theory shows in comparisons across gender, age, and countries as well as cohort, findings that can less easily be explained by recall and mortality bias. Despite these limitations, the ability to reconstruct smoking histories from cross-sectional data makes it possible to compare smoking disparities across the life course, cohorts, and countries in ways that increase our understanding of gender and educational differences in health.

\section{Acknowledgments}

This project received travel support from the Institut National d'Etudes Demographiques Direction des Relations Internationales et des Partenariates, and funding from the Institut National d'Etudes Demographiques and Institut National du Cancer (COTCEDIS Project "Consommation de tabac et de cannabis: evolution et dynamiques de construction des inegalites sociales," Grant No. 2011-250).

\section{References}

Ai C, Norton EC. Interaction terms in logit and probit models. Economics Letters. 2003; 80(1):123129.

Allison PD. Discrete-time methods for the analysis of event histories. Sociological Methodology. 1982; 13(1):61-98.

Allison PD. Comparing logit and probit coefficients across groups. Sociological Methods and Research. 1999; 28:186-208.

Bachman, JG., O'Malley, PM., Schulenberg, JE., Johnston, LD., Bryant, AL., Merlin, AC. The decline of substance use in young adulthood: Changes in social activities, roles, and beliefs. Mahwah, NJ: Lawrence Erlbaum; 2002.

Beck, F., Gautier, A., Guignard, R., Richard, JB. Une méthode de prise en compte du dégroupage total dans le plan de sondage des enquêtes téléphoniques auprès des ménages. In: Tremblay, ME.Lavallée, P., El Hadj Tirari, M., editors. Pratiques et méthodes de sondage. Paris: Dunod; 2011a. p. 310-314.

Beck F, Guignard R, Richard JB, Tovar ML, Spilka S. Les niveaux d'usage des drogues en france en 2010 - exploitation des données du baromètre santé. Tendances. 2011b; 76:1-6. 
Bilal U, Fernández E, Beltran P, Navas-Acien A, Bolumar F, Franco M. Validation of a method for reconstructing historical rates of smoking prevalence. American Journal of Epidemiology. 2014; 179(1):15-19. [PubMed: 24077091]

Bosdriesz JR, Willemsen MC, Stronks K, Kunst AE. Socioeconomic inequalities in smoking cessation in 11 European countries from 1987 to 2012. Journal of Epidemiology and Community Health. 2015; 69:886-892. [PubMed: 25841241]

Bricard D, Jusot F, Beck F, Khlat M, Legleye S. Educational inequalities in smoking over the lifecycle: An analysis by cohort and gender. International Journal of Public Health. 2015; 61(1):101-109. [PubMed: 26310848]

Businelle MS, Kendzor DE, Reitzel LR, Costello TJ, Cofta-Woerpel L, Li Y, Mazas CA, Vidrine JI, Cinciripini PM, Greisinger AJ, Wetter DW. Mechanisms linking socioeconomic status to smoking cessation: A structural equation modeling approach. Health Psychology. 2010; 29(3):262-273. [PubMed: 20496980]

Chassin L, Presson CC, Pitts SC, Sherman SJ. The natural history of cigarette smoking from adolescence to adulthood in a Midwestern community sample: Multiple trajectories and their psychosocial correlates. Health Psychology. 2000; 19:222-231.

Chen P, Jacobson KC. Developmental trajectories of substance use from early adolescence to young adulthood: Gender and racial/ethnic differences. Journal of Adolescent Health. 2011; 50:154-163. [PubMed: 22265111]

Christopoulou R, Han J, Jaber A, Lillard D. Dying for a smoke: How much does differential mortality of smokers affect estimated life-course smoking prevalence? Preventive Medicine. 2011; 52(1):6670. [PubMed: 21094661]

Costello DM, Dierker LC, Jones BL, Rose JS. Trajectories of smoking from adolescence to early adulthood and their psychosocial risk factors. Health Psychology. 2008; 27:811-818. [PubMed: 19025277]

Dinno A, Glantz S. Tobacco control policies are egalitarian: A vulnerabilities perspective on clean indoor air laws, cigarette prices, and tobacco use disparities. Social Science \& Medicine. 2009; 68(8):1439-1447. [PubMed: 19282078]

DiPrete TA, Eirich GM. Cumulative advantage as a mechanism for inequality: A review of theoretical and empirical developments. Annual Review of Sociology. 2006; 32:271-297.

Droomers M, Schrijvers CTM, Casswell S, Mackenbach JP. Father's occupational group and daily smoking during adolescence: Patterns and predictors. American Journal of Public Health. 2005; 95:681-688. [PubMed: 15798130]

Elder GH Jr. Time, human agency, and social change: Perspectives on the life course. Social Psychological Quarterly. 1994; 57:4-15.

Ferrence, RG. Deadly fashion: The rise and fall of cigarette smoking in North America. New York: Garland Publishing; 1989.

Frohlich KL, Potvin L. The inequality paradox: The population approach and vulnerable populations. American Journal of Public Health. 2008; 98:216-221. [PubMed: 18172133]

Forey, B., Hamling, J., Hamling, J., Thornton, A., Lee, P. International smoking statistics: WEB edition 2006-2015. 2016. Available Online http://www.pnlee.co.uk/ISS3.htm

Giskes K, Kunst AE, Benach J, Borrell C, Costa G, Dahl E, Mackenbach JP. Trends in smoking behaviour between 1985 and 2000 in nine European countries by education. Journal of Epidemiology and Community Health. 2005; 59:395-401. [PubMed: 15831689]

Glei DA, Horiuchi S. The narrowing sex differential in life expectancy in high-income populations: Effects of differences in the age pattern of mortality. Population Studies. 2007; 61(2):141-159. [PubMed: 17558883]

Graham H, Hawkins SS, Law C. Life course influences on women's smoking before, during and after pregnancy. Social Science \& Medicine. 2010; 70:582-587. [PubMed: 19932931]

Griesbach D, Amos A, Currie C. Adolescent smoking and family structure in Europe. Social Science \& Medicine. 2003; 56:41-52. [PubMed: 12435550]

Hanson MD, Chen E. Socioeconomic status and health behaviors in adolescence: A review of the literature. Journal of Behavioral Medicine. 2007; 30:263-285. [PubMed: 17514418] 
Harman J, Graham H, Francis B, Inskip HM, the SWS Study Group. Socioeconomic gradients in smoking among young women: A British survey. Social Science \& Medicine. 2006; 63:27912800. [PubMed: 16962221]

Hibeli, B., Guttormsson, U., Ahlström, S., Balakireva, O., Bjarnason, T., Kokkevi, A., Kraus, L. The 2011 ESPAD report: Substance use among students in 36 European countries. 2012. Available at http://espad.org/Uploads/ESPAD_reports/2011/ The_2011_ESPAD_Report_FULL_2012_10_29.pdf

Hu MC, Muthén B, Schaffran C, Griesler PC, Kandel DB. Developmental trajectories of criteria of nicotine dependence in adolescence. Drug and Alcohol Dependence. 2008; 98:94-104. [PubMed: 18602225]

Ingall G, Cropley M. Exploring the barriers of quitting smoking during pregnancy: A systematic review of qualitative studies. Women and Birth. 2010; 23:45-52. [PubMed: 19879206]

Jacobson, P., Lantz, PM., Warner, KE., Wasserman, J., Pollack, HA., Ahlstrom, AK. Combating teen smoking: Research and policy strategies. Ann Arbor: University of Michigan Press; 2001.

Jha P, Peto R, Zatonski W, Boreham J, Jarvis MJ, Lopez AD. Social inequalities in male mortality, and in male mortality from smoking: Indirect estimation from national death rates in England and Wales, Poland, and North America. Lancet. 2006; 368:367-370. [PubMed: 16876664]

Johnston LD. Changing demographic patterns of adolescent smoking over the past 23 years: National trends from the Monitoring the Future study. Smoking and Tobacco Control Monograph. 2001; 14:9-33.

Johnston, LD., O'Malley, PM., Miech, RA., Bachman, JG., Schulenberg, JE. Monitoring the Future national results on drug use: 1975-2013: Overview, key findings on adolescent drug use. Ann Arbor: Institute for Social Research, University of Michigan; 2014.

Kerckhoff AC, Ezell ED, Brown JS. Toward an improved measure of educational attainment in social stratification research. Social Science Research. 2002; 31(1):99-123.

Lacey RE, Cable N, Stafford M, Bartley M, Pikhart H. Childhood socio-economic position and adult smoking: Are childhood psychosocial factors important? Evidence from British birth cohort. European Journal of Public Health. 2010; 21:725-731. [PubMed: 21131349]

Legleye S, Khlat M, Beck F, Peretti-Watel P. Widening inequalities in smoking initiation and cessation patterns: A cohort and gender analysis in France. Drug and Alcohol Dependence. 2011; 117(2-3): 233-241. [PubMed: 21420251]

Lopez AD, Collishaw NE, Piha T. A descriptive model of the cigarette epidemic in developed countries. Tobacco Control. 1994; 3(3):242-247.

Luy M, Wegner-Siegmundt C. The impact of smoking on gender differences in life expectancy: More heterogeneous than often stated. European Journal of Public Health. 2015; 25(4):706-710. [PubMed: 25505018]

Mackenbach JP. The persistence of health inequalities in modern welfare states: The explanation of a paradox. Social Science \& Medicine. 2012; 75:761-769. [PubMed: 22475407]

Mackenbach J, Huisman M, Andersen O, Bopp M, Borgan JK, Borrell C, Kunst AE. Inequalities in lung cancer mortality by educational level in 10 European populations. European Journal of Cancer. 2004; 40:126-135. [PubMed: 14687796]

Maralani V. Educational inequalities in smoking: The role of initiation versus quitting. Social Science \& Medicine. 2013; 84:129-137. [PubMed: 23466258]

Masters RK, Link BG, Phelan JC. Trends in education gradients of 'preventable' mortality: A test of fundamental cause theory. Social Science \& Medicine. 2015; 127:19-28. [PubMed: 25556675]

Moon-Howard J. African-American women and smoking: Starting later. American Journal of Public Health. 2003; 93(3):418-420. [PubMed: 12604485]

Montez JK, Hummer RA, Hayward MD, Woo H, Rogers RG. Trends in the educational gradient of U.S. adult mortality from 1986 through 2006 by race, gender, and age group. Research on Aging. 2011; 33(2):145-171. [PubMed: 21897495]

Montez JK, Barnes K. The benefits of educational attainment for U.S. adult mortality: Are they contingent on the broader environment? Population Research and Policy Review. 2016; 35:73100 . 
National Center for Health Statistics. 2010 National Health Interview Survey (NHIS) Public Use Data Release: NHIS survey description. 2013. ftp://ftp.cdc.gov/pub/Health_Statistics/NCHS/ Dataset_Documentation/NHIS/2010/srvydesc.pdf

Nichter, M. Lighting up: The rise of social smoking on college campuses. New York: NYU Press; 2015.

Oaks, L. Smoking and pregnancy: The politics of fetal protection New Brunswick. New Jersey: Rutgers University Press; 2001.

Pampel FC. Inequality, diffusion, and the status gradient in smoking. Social Problems. 2002; 49:35-57.

Pampel FC. Declining sex differences in lung cancer mortality in high income nations. Demography. 2003; 40:45-65. [PubMed: 12647513]

Pampel FC. Diffusion, cohort change, and social patterns of smoking. Social Science Research. 2005; 34:117-139. [PubMed: 22485056]

Pampel FC, Mollborn S, Lawrence EA. Life course transitions in early adulthood and SES disparities in tobacco use. Social Science Research. 2014; 43:45-59. [PubMed: 24267752]

Pampel F, Legleye S, Goffette C, Pointek D, Kraus L, Khlat M. Cohort changes in educational disparities in smoking: France, Germany and the United States. Social Science \& Medicine. 2015; 127:41-50. [PubMed: 25037853]

Pappas G, Queen S, Hadden W, Fisher G. The increasing disparity in mortality between socioeconomic groups in the United States, 1960 and 1986. New England Journal of Medicine. 1993; 329:103109. [PubMed: 8510686]

Peretti-Watel P, Constance J. 'It's all we got left': Why poor smokers are less sensitive to cigarette price increases. International Journal of Environmental Research and Public Health. 2009; 6(2): 608-621. [PubMed: 19440404]

Peretti-Watel P, Constance J, Seror V, Beck F. Working conditions, job dissatisfaction and smoking behaviours among french clerks and manual workers. Journal of Occupational and Environmental Medicine. 2009; 51(3):343-350. [PubMed: 19225420]

Potter BK, Pederson LL, Chan SSH, Aubut JAL, Koval JJ. Does a relationship exist between body weight, concerns about weight, and smoking among adolescents? An integration of the literature with an emphasis on gender. Nicotine \& Tobacco Research. 2004; 6(3):397-425. [PubMed: 15203775]

Reid JL, Hammond D, Boudreau C, Fong G, Siahpush M. Socioeconomic disparities in quit intentions, quit attempts, and smoking abstinence among smokers in four western countries: Findings from the international tobacco control four country survey. Nicotine and Tobacco Research. 2010; 12(Suppl. 1):S20-S33. [PubMed: 20889477]

Rose G. Sick individuals and sick populations. International Journal of Epidemiology. 1985; 14:32-38. [PubMed: 3872850]

Rose, G. The strategy of preventive medicine. Oxford, England: Oxford University Press; 1992.

Schaap M, Kunst A, Leinsalu M, Regidor E, Ekholm O, Dzurova D, Mackenbach J. Effect of nationwide tobacco control policies on smoking cessation in high and low educated groups in 18 European countries. Tobacco Control. 2008; 17:248-255. [PubMed: 18483129]

Slovic, P., editor. Smoking: Risk, perception, and policy. Thousands Oaks: Sage; 2001.

Soteriades ES, DiFranza JR. Parent's socioeconomic status, adolescents' disposable income, and adolescents' smoking status in Massachusetts. American Journal of Public Health. 2003; 93:11551160. [PubMed: 12835202]

Staff J, Schulenberg JE, Maslowsky J, Bachman JG, O'Malley PM, Maggs JL, Johnston LD. Substance use changes and social role transitions: proximal developmental effects on ongoing trajectories from late adolescence through early adulthood. Development and Psychopathology. 2010; 22:917932. [PubMed: 20883590]

Thomas S, Fayter D, Misso K, Ogilvie D, Petticrew M, Sowden A, Whitehead M, Worthy G. Population tobacco control interventions and their effects on social inequalities in smoking: systematic review. Tobacco Control. 2008; 17:230-237. [PubMed: 18426867]

Thun MJ, Carter BD, Feskanich D, Freedman ND, Prentice R, Lopez AD, Susan MGapstur. 50-year trends in smoking-related mortality in the United States. New England Journal of Medicine. 2013; 368:351-364. [PubMed: 23343064] 
Thun M, Peto R, Boreham J, Lopez AD. Stages of the cigarette epidemic on entering its second century. Tobacco Control. 2012; 21:96-101. [PubMed: 22345230]

Tuinstra J, Groothoff JW, van den Heuval W, Post D. Socio-economic differences in health risk behavior in adolescence: Do they exist? Social Science \& Medicine. 1998; 47:67-74. [PubMed: 9683380]

Umberson D, Crosnoe R, Reczek C. Social relationships and health behavior across the life course. Annual Review of Sociology. 2010; 36:139-157.

UNESCO Institute for Statistics. ISCED 2011 operational manual: Guidelines for classifying national education programmes and related qualifications. Paris: OECD Publishing; 2015. doi:http:// dx.doi.org/10.1787/9789264228368-en

U.S. Department of Health and Human Services (USDHHS). Smoking - 50 years of progress: A report of the Surgeon General. Rockville, MD: U.S. Department of Health and Human Services, Public Health Service, Office of the Surgeon General; 2014.

Willson AE, Shuey KM, Elder GH Jr. Cumulative advantage processes as mechanisms of inequality in life course health. American Journal of Sociology. 2007; 112:1886-1924.

Wong MD, Shapiro MF, Boscardin WJ, Ettner SL. Contribution of major diseases to disparities in mortality. New England Journal of Medicine. 2002; 347:1585-1592. [PubMed: 12432046]

World Health Organization(WHO). Deaths from tobacco in Europe. 2016. Available online http:// www.euro.who.int/en/health-topics/disease-prevention/tobacco/news/news/2012/04/deaths-fromtobacco-in-europe

Zajacova A, Walsemann KM, Dowd JB. The long arm of adolescent health among men and women: Does attained status explain its association with mid-adulthood health? Population Research and Policy Review. 2015; 34:19-48.

Popul Res Policy Rev. Author manuscript; available in PMC 2018 June 01. 

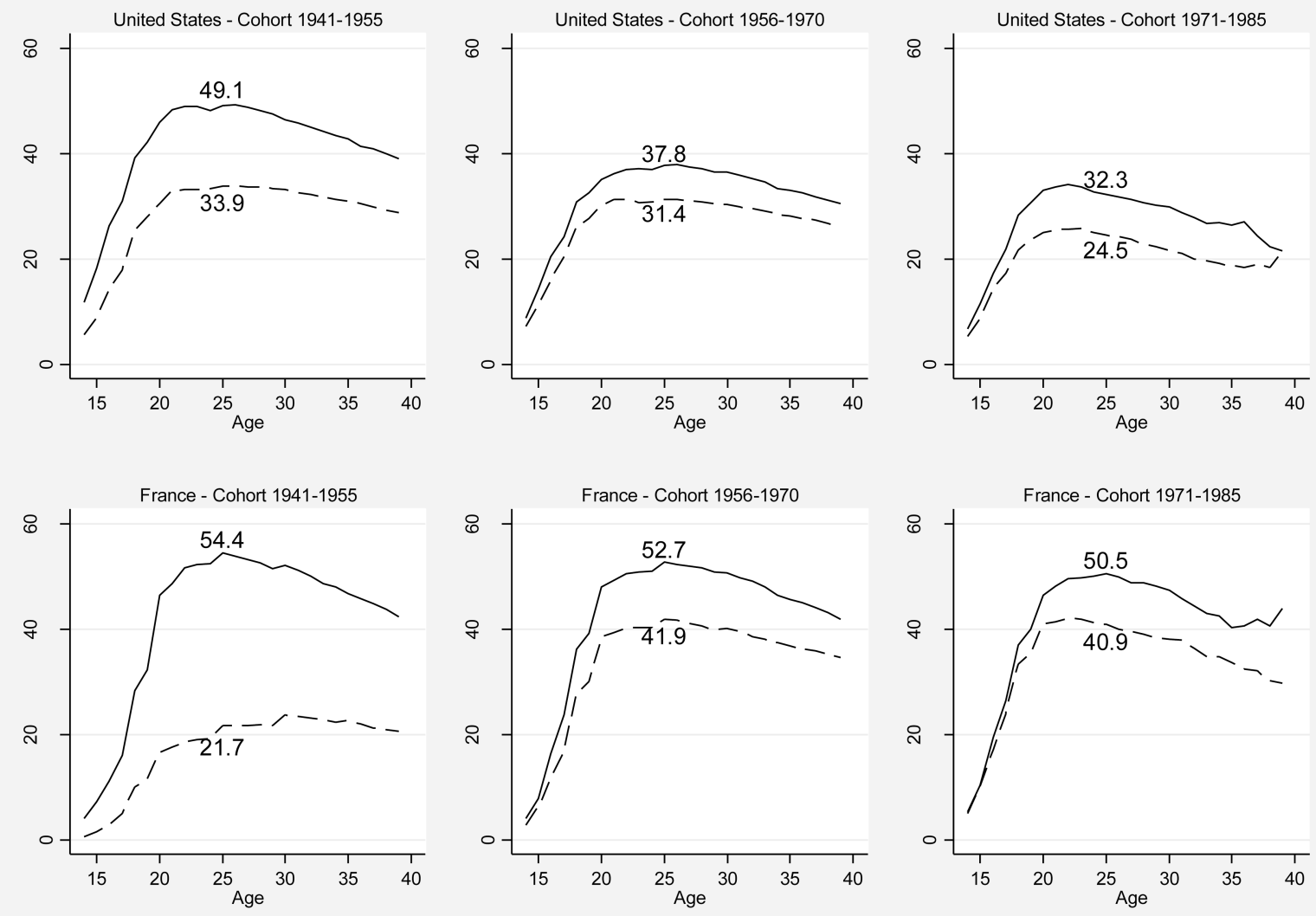

Figure 1. Smoking prevalence by age for gender and cohort groups - All levels of education Note: Men $=$ solid line, women $=$ dotted line 

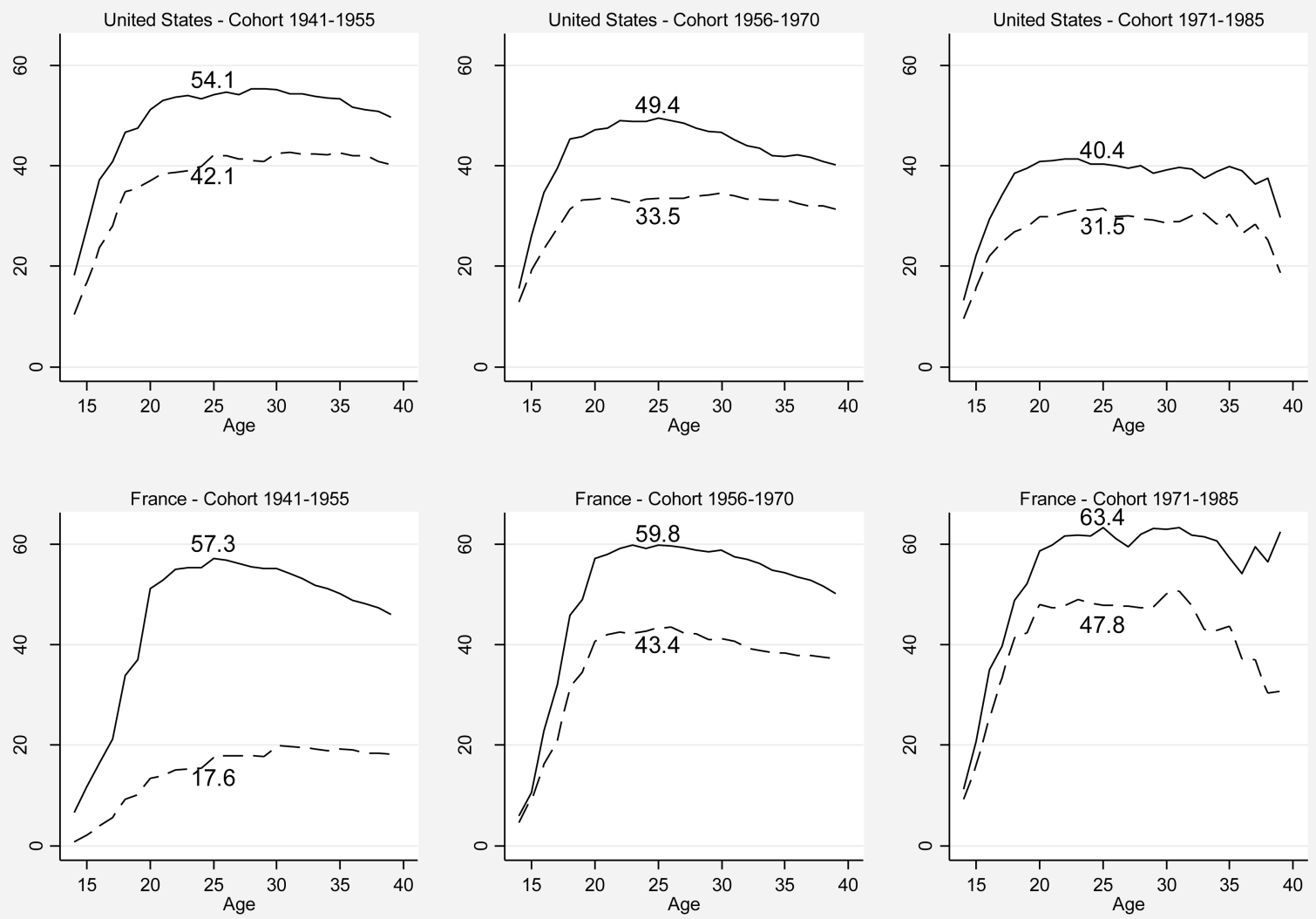

Figure 2. Smoking prevalence by age for gender and cohort groups - Low education

Note: Men = solid line, women $=$ dotted line

Popul Res Policy Rev. Author manuscript; available in PMC 2018 June 01. 

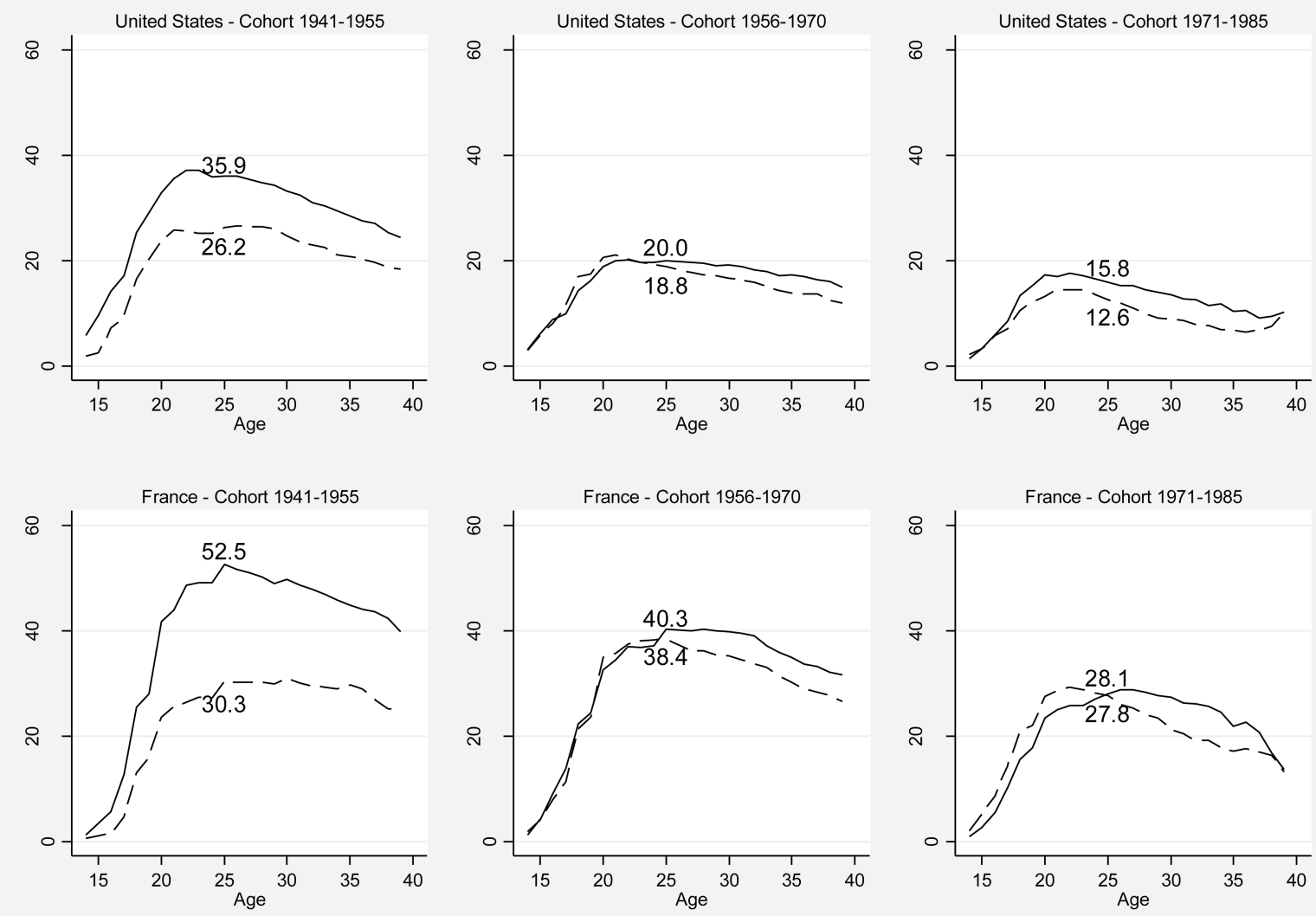

Figure 3. Smoking prevalence by age for gender and cohort groups - High education

Note: Men $=$ solid line, women $=$ dotted line 


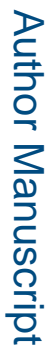

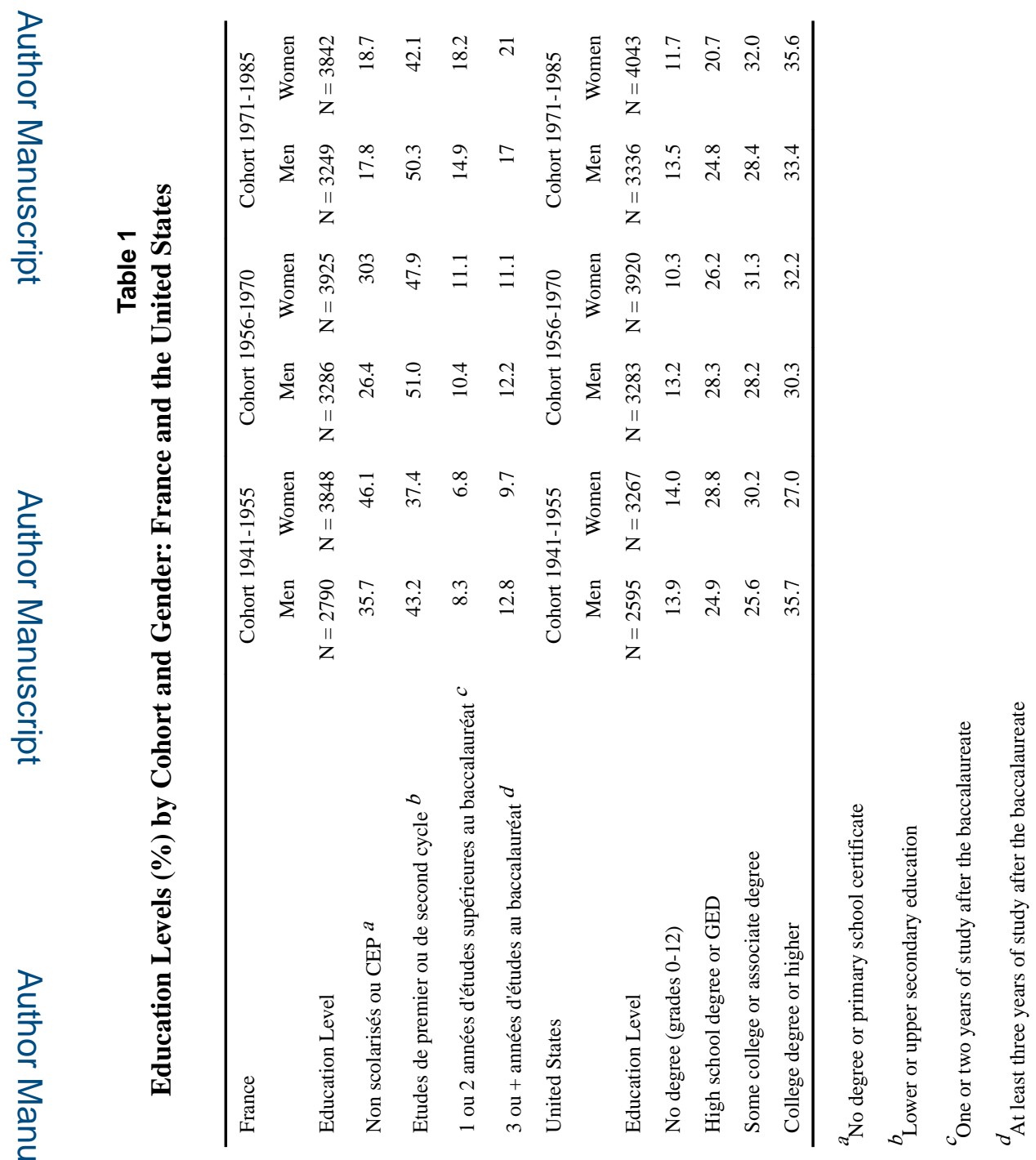

Popul Res Policy Rev. Author manuscript; available in PMC 2018 June 01. 

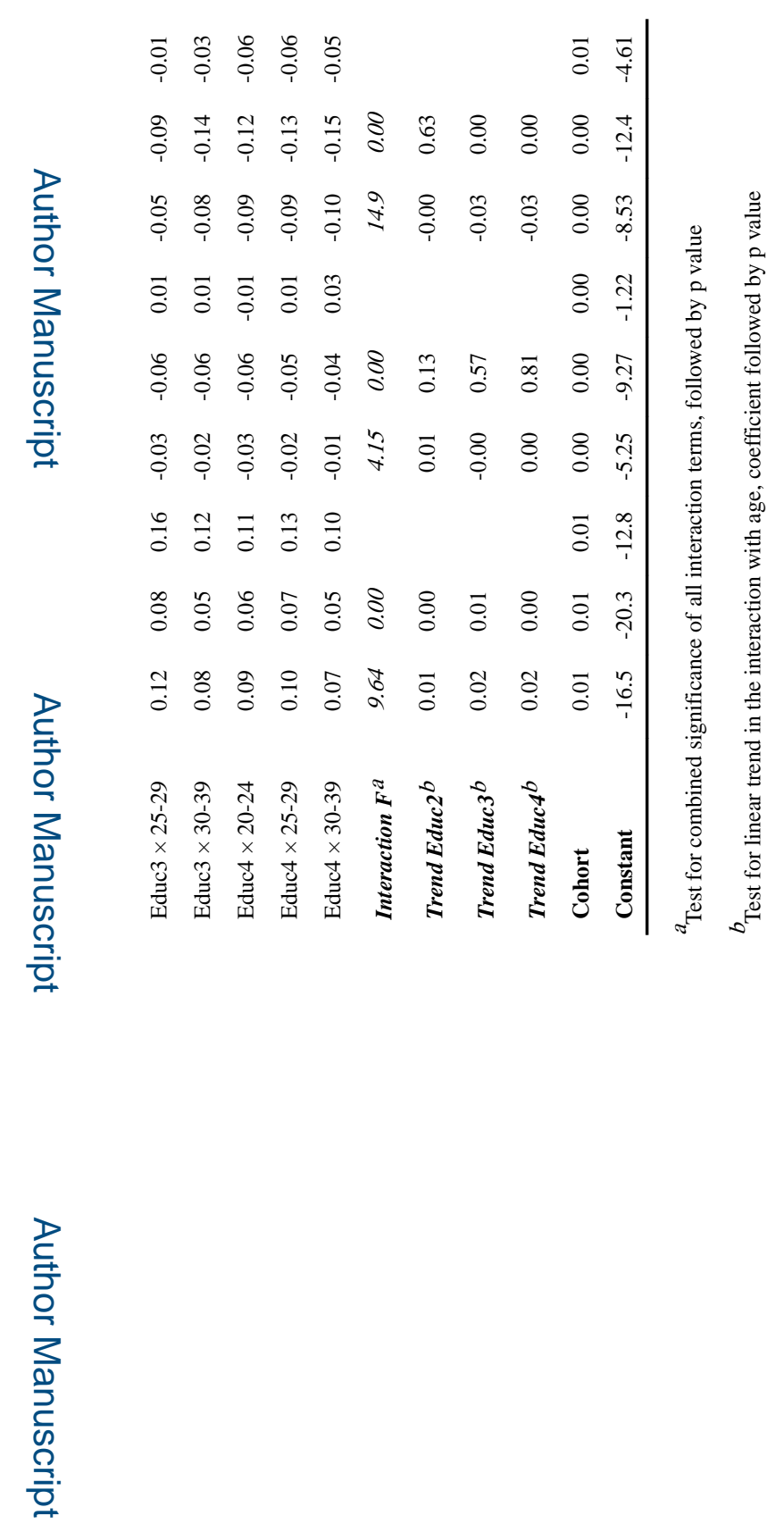

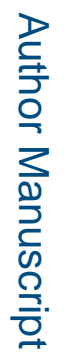

Popul Res Policy Rev. Author manuscript; available in PMC 2018 June 01. 

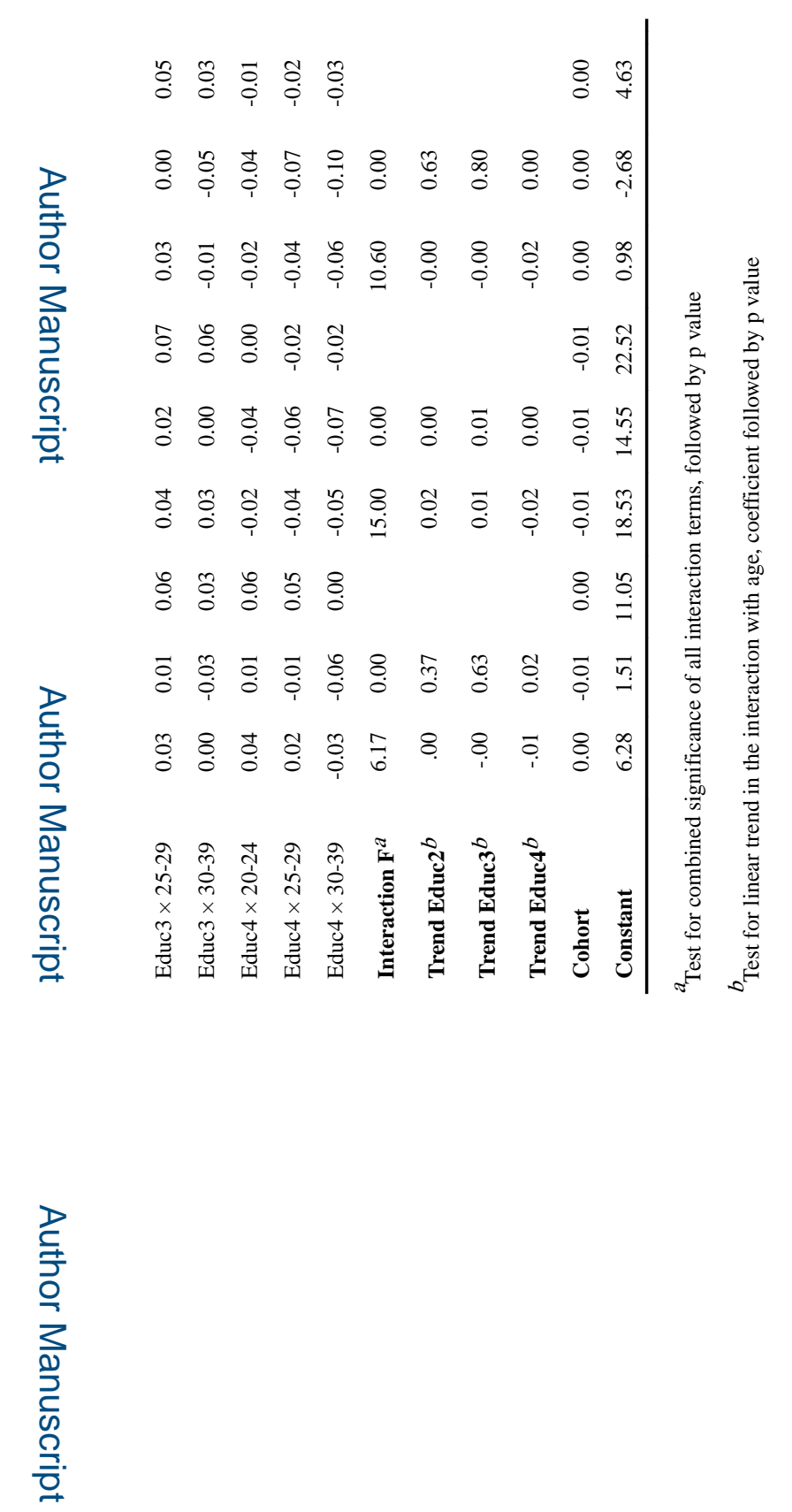

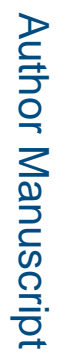

Popul Res Policy Rev. Author manuscript; available in PMC 2018 June 01. 